\title{
Avaliação de Sistema de Cisternas Para Captação de Água de Chuva Instalados em Comunidades Rurais de Mato Grosso - Brasil
}

\section{Cisterns Evaluation System for Rainwater Catchment installed in Mato Grosso Rural Communities - Brazil}

\author{
${ }^{1}$ Marciely Ferreira Alves, ${ }^{2}$ Margarida Marchetto, ${ }^{3}$ Samir Curi, ${ }^{4}$ Gabriel Pimentel, ${ }^{5}$ Rafael Vinicius
}

Rodrigues.

\begin{abstract}
${ }^{1,5}$ Formandos no Departamento de Engenharia Sanitária e Ambiental - DESA, Faculdade de Arquitetura Engenharia e Tecnologia - FAET da Universidade Federal de Mato Grosso - UFMT (eng.marciely@ gmail.com) ${ }^{2}$ Profa doutora do DESA, pesquisadora no Programa de Pós Graduação em Recursos Hídricos,PPGRH/FAET/UFMT(m_marchetto@ufmt,br) ${ }^{3}$ Instituto Nacional de Reforma Agrária - INCRA (samircuiaba@gmail.com) ${ }^{4}$ Mestrando no PPGRH/FAET/UFMT(gabriel.pime@ hotmail.com).
\end{abstract}

Recebido em fevereiro 2016Aceito em: Abril de 2016 Publicado em: junho 2016

\begin{abstract}
Resumo: O estado de Mato Grosso é um dos maiores estados brasileiros, possuindo um grande volume de água doce. Todavia, dada a sua dimensão geográfica e as suas condições climáticas diferenciadas, algumas regiões sofrem problemas de escassez hídrica, como é o caso do cerrado mato-grossense, fazendo com que muitas pessoas enfrentem, diariamente, dificuldades para ter ao acesso à água com qualidade biológica, física e química adequada. Nesta região os recursos hídricos superficiais são escassos, com mananciais intermitentes que podem permanecer secos durante grande parte do ano, frente à escassa disponibilidade de água as comunidades desenvolvem mecanismos adaptativos, a fim de mudar sua maneira de encarar as dificuldades referentes à obtenção do recurso, terminam por se restringir ao senso comum a respeito da qualidade do mesmo. Sendo assim, é importante compreender a percepção de uma dada comunidade do acesso a água de chuva, visto que este é um fator imprescindível para o desenvolvimento e qualidade de vida da população.Desta forma, o objetivo do presente trabalho é tecer uma análise sobre o projeto piloto de cisterna com aproveitamento de água da chuva para a agricultura familiar, desenvolvido pelo Incra/MT em parceria com o Ministério Público Estadual, implantado em uma comunidade rural no Município de Várzea Grande estado de Mato Grosso Brasil.
\end{abstract}

Palavras Chave. Saneamento rural, Técnicas de aproveitamento de água de chuva, sustentabilidade.

\begin{abstract}
The state of Mato Grosso is one of the largest Brazilian states, having a large volume of fresh water. However, given their geographical dimension and their different climatic conditions, some regions suffer problems of water scarcity, as in the case of Mato Grosso cerrado, causing many people face daily difficulties to have access to water quality biological, physical and chemical proper. In Mato Grosso cerrado region, the surface water resources are scarce, with non-perennial springs that can remain dry for much of the year, compared to the scarce availability of water communities develop adaptive mechanisms in order to change their way of looking the difficulties related to obtaining the resource, end up be limited to common sense about the quality. So then, it is important to understand the perception of a given community about the feature, since this is an essential factor for the development and quality of life of the population.Thus, the purpose of this article is to weave an analysis of the tanker pilot project with rainwater utilization for family farms, developed by Incra / MT in partnership with the State Prosecutor, deployed in a rural community of Mato Grosso - Brazil.
\end{abstract}

Key Words: Rural sanitation, rain water utilization techniques, sustainability.

\section{INTRODUÇÃO}

A reforma agrária no Brasil proporciona acesso a terrapara milhões de famílias para que possam sobreviver através da agricultura familiar, basicamente, o assentamento rural é umconjunto de unidades agrícolasindependentes entre si, instaladas pelo Incra onde originalmente existia um imóvel rural que pertencia a um único 
proprietário (Incra 2015), porém, esta alocação se dá sem qualquer infraestrutura sanitária para as famílias beneficiadas. A falta de água em muitos destes assentamentos é um problema constante, pois em sua maioria, as terras distribuídas pelo governo federal estão distantes de fontes seguras de água potável, que a cada dia estão mais reduzidas pelo alto grau de contaminações que ocorrem por agrotóxicos e outros diversos impactos ambientais.

Segundo o Ministério do Meio Ambiente o estado de Mato Grosso é um dos maiores estados brasileiros, possuindo grande volume de água doce. Todavia, dada a sua dimensão geográfica e as suas condições climáticas diferenciadas, algumas regiões sofrem problemas de escassez hídrica, como é o caso do cerrado mato-grossense, fazendo com que muitas pessoas enfrentem, diariamente, dificuldades para ter acesso à água com qualidade biológica, física e química adequada (MMA, 2012)

$\mathrm{Na}$ região do cerrado matogrossense, os recursos hídricos superficiais são escassos, com mananciais intermitentes que podem permanecer secos durante grande parte do ano, frente à escassa disponibilidade de águas comunidades desenvolvem mecanismosadaptativos, a fim de mudar sua maneira de encarar as dificuldades referentes à obtenção do recurso,terminam por se restringir ao senso comum a respeito da qualidade do mesmo. Sendo assim, é importante compreender a percepção de uma dada comunidade acerca do recurso, visto que este é o fator imprescindível para o desenvolvimento e qualidade de vida da população.

A disponibilidade de água potável ao consumo do ser humanopode ser considerada $\mathrm{o}$ principal fator à sobrevivência e à melhoria da qualidade de vida daspopulações rurais, sobretudo nas regiões áridas e semiáridas. Principalmente quando se analisam aprecariedade do sistema de abastecimento de água, de esgotos sanitários, de destinação do lixo, ausência ou insuficiência de medidas de proteção contra os níveis de poluição e contaminação hídrica (FREITAS et al., 2012).

Nas últimas décadas foram observadas mudanças relativas aoparadigma de combate a seca, pois, se anteriormente a luta era para combater aseca, agora a ênfase se volta para a convivência com o semiárido, considerando-se a adoção de políticas públicas e práticas sustentáveis esta convivência torna-seuma realidade. Neste contexto, a captação da água de chuva torna-se umaalternativa viável que somada a outras políticas públicas, contribuiu com odesenvolvimento sustentável da região, sendo a construção de cisternas uma destasalternativas com melhor relação custo-benefício. Assim, a instalação de sistemas decaptação de água de chuva e seu uso racional representa uma contribuição efetiva para o acesso equitativo ao uso da água por todos os cidadãos (PONTES \&MACHADO, 2009).

A NBR 15527/07 surgiu como a primeira diretriz brasileira específica, que fornece os requisitos para oaproveitamento de água de chuva de coberturas em áreas urbanas, para fins não potáveis tais como descargas embacias sanitárias, irrigação de plantas ornamentais, lavagem de veículos e calçadas, limpezas de pátios e usos industriais. Em resumo, a norma trata das condições gerais que o sistema de aproveitamento devesatisfazer, principalmente no que se refere a calhas e condutores, reservatórios, instalações prediais e manutenção. A norma se aplica a usos não-potáveis, em que a água de chuva possa ser utilizada após tratamento adequado.

A Portaria MS No2914/11 do Ministério daSaúde trata do padrão de potabilidade da água e dopadrão para o 
consumo humano. Estabelece os limites devários parâmetros, que afetam a qualidade microbiológica da água e os limites para algumas substâncias químicas que representam riscos à saúde.

Desta forma, o objetivo do presente artigo é tecer uma análise sobre o projeto piloto de cisterna com aproveitamento de água da chuva para a agricultura familiar, desenvolvido pelo Incra/MT em parceria com o Ministério Público Estadual, implantado em uma comunidade rural de Mato Grosso - Brasil

\section{MATERIAS E MÉTODOS}

O trabalho foi desenvolvido realizando-se as seguintes etapas:

(i) Revisão de literatura acerca do tema; (ii) escolha da área a ser estudada;

(ii) Elaboração do questionário a ser aplicado;

(iii) Visitas ao local de estudo para realização de entrevistas com a população através da aplicação de questionários;

(iv)Análise dos resultados.

Para desenvolvimento da revisão da literatura foram consultados artigos, teses e dissertações sobre o tema. A área delimitada para o estudo foi escolhida com base no interesse sobre o andamento de cisternas instaladas em comunidades rurais.

A pesquisa foi desenvolvida no Assentamento Nossa Senhora Aparecida I, localizado na BR-364 sentido Várzea Grande - Jangada, a $23 \mathrm{~km}$ da sede de Várzea Grande. Administrado pelo INCRA, Instituto Nacional de Colonização e Reforma Agrária (Figura 1).

O projeto piloto de cisterna com aproveitamento de água da chuva para a agricultura familiar, estudado é composto por Captação da água da chuva; Condução da água da chuva; Bomba; Reservatório de 8000 L. (Figura 2)

Figura 1- Localização do município de Várzea Grande - Assentamento Rural Nossa Senhora I.

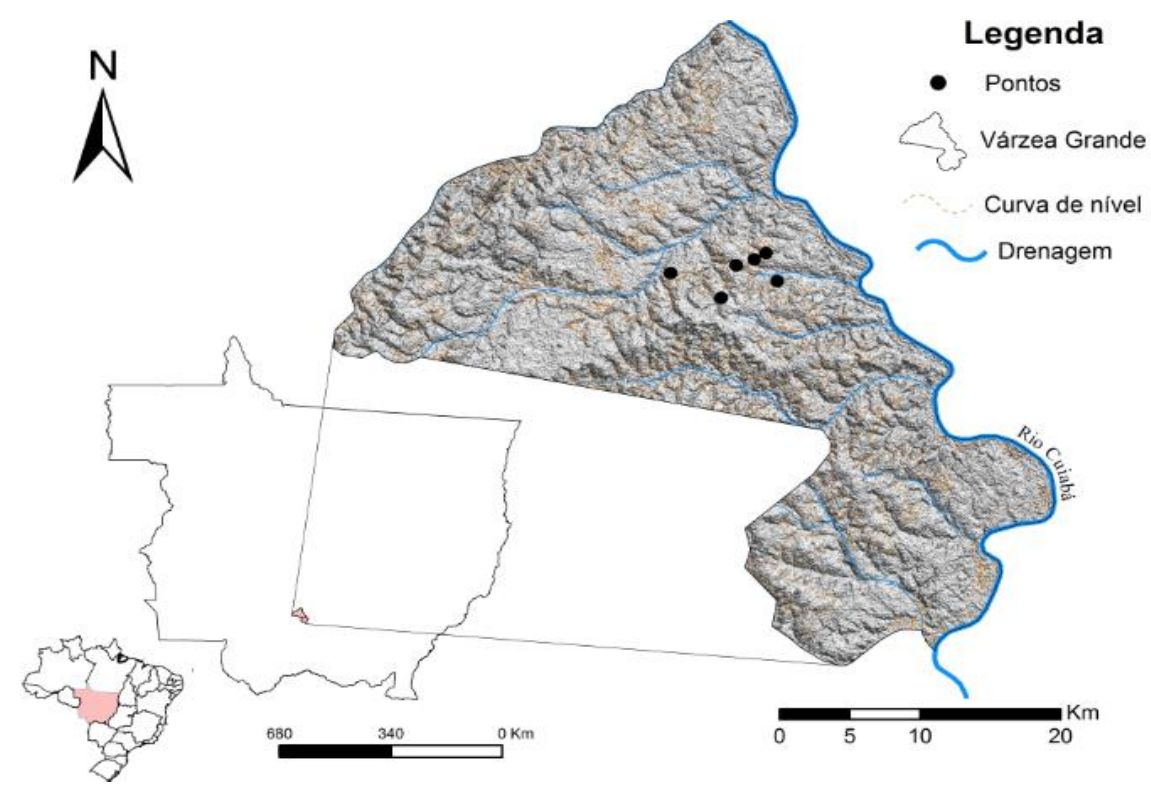

Fonte: Elaborado por Alves, Marciely F. (2015)

A captação da água da chuva ocorre através das superfícies coletoras de coberturas e é direcionada através de calhas e condutores até os locais de armazenamento. $\mathrm{O}$ telhado das residências 
em estudo é do tipo cerâmico, tradicional no Brasil. Um ponto a favor de todas as moradias é a inexistência de árvores de grande porte no seu entorno, visto que seriam uma fonte constante de contaminação e materiais grosseiros (folhas).

Figura 02 - Esquematização do Sistema de coleta de água de chuva (a) cisterna; (b) pré-filtro (c) Layout do sistema

(a)

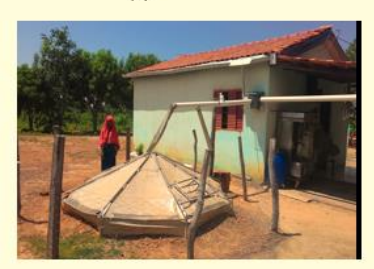

(C)



Fonte: a e b) Alves Marciely F.2015.

b) Saneamento

Condução da água da chuva; A calha tem a função de conduzir a água de chuva proveniente do telhado e a tubulação a destina ao reservatório. Ambos são fabricados de PVC, não sofrendo corrosão, sendo duráveis e de fácil instalação. $O$ material adquirido é específico para a drenagem pluvial, assegurando a eficiência da coleta.

$\mathrm{O}$ questionário utilizado foi $\mathrm{o}$ modelo proposto pelo trabalho de Impactos Socioeconômicos do projeto cisternas em Comunidades do município de Ibipeba, Bahia, do Instituto Nacional do Semiárido. Dentre as diversas metodologias apresentadas optou-se pela avaliação da situação atual do sistema de cisternas instaladas em comunidades rurais pelo Incra - MT.

Foram realizadas entrevistas em um período de um mês, sendo entrevistado os beneficiários do projeto piloto de cisternas.

Os resultados das pesquisas foram compilados em gráficos para auxiliar na análise e discussão.

\section{Questionário aplicado}

O questionário aplicado foi realizado de forma que as perguntas localizassem potenciais dificuldades que $o$ projeto possa vir a apresentar desde de sua instalação. O questionário possui 13 (treze) perguntas. A aplicação do questionário foi feita deforma estruturada, e o entrevistado respondeu verbalmente as perguntas do entrevistador (Figura 3), que as transcrevia para a ficha. $\mathrm{O}$ questionário aplicado segue no Quadro 1, em anexo (adaptado SILVA, 2013).

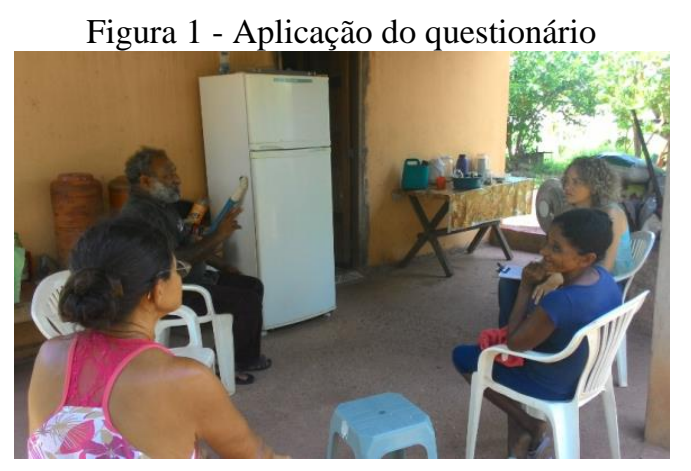

Fonte: Alves, Marciely F.(2015)

\section{RESULTADOS}

\section{Eixo Social}

O perfil das famílias entrevistadas que fazem parte da comunidade pesquisada está apresentado na Figura 4, em que $50 \%$ são de adultos, $25 \%$ de jovens e $25 \%$ de idosos. A renda familiar composta de 1 a 4salários mínimo, sendo os mesmo sem sua maioria adultos e economicamente ativos, embora, a principal fonte de renda seja os benefícios sociais, sendo que $50 \%$ são aposentadorias. 
Portanto, $25 \%$ dos componentes das famílias, que correspondem aos idosos, são responsáveis pela maior parcela de renda da família. Em algumas famílias, a fonte de renda é de outra natureza, alguns integrantes possuem trabalho, e algumas famílias vendem parte de sua produção.



Fonte: Alves, Marciely F.(2016)

Foi possível verificar na pesquisa com as famílias, que apesar do acesso à água das cisternas, as pessoas sentem necessidade da segurança financeira, da renda fixa para assegurar a aquisição dos alimentos que não são produzidos pela família.

\section{Eixo da Tecnologia Cisterna}

Cerca de $20 \%$ das famílias não tinham nenhuma fonte de abastecimento de água antes das cisternas, $40 \%$ eram abastecidas por córregos (os córregos desta região são denominados intermitentes, secando em época de estiagem), $20 \%$ por meio de represas e $20 \%$ por meio de poços tubulares não profundos (Figura 6). Deste modo pode-se observar que as cisternas são elementos essenciais para garantir a segurança hídrica das famílias que não possuíam nenhuma outra forma de abastecimento de água na época de estiagem.

Figura06 - Fontes de abastecimento anteriores à implantação da cisterna



Fonte: Alves, Marciely F.(2016)

O acesso a água para famílias que não possui este recurso é um ganho social, pois proporciona qualidade de vida familiar para as mesmas, que anteriormente não tinha acesso a nenhuma fonte de água.

Embora dada a devida importância das cisternas, o manejo adequado, como limpeza, manutenção e reparos estão apresentados na Figura 7. Somente 20\% das famílias realizaram lavagem da cisterna, o que pode ser justificado pelo intuito de não desperdiçar água para este fim, falta de treinamento conscientização. Cerca de $80 \%$ das famílias realizaram manutenção nas cisternas, o que se resume a fixação das tubulações e locação das mesmas, suportes para os condutos e conserto na lona da parte interior de uma cisterna. Notou-se que este reparo se deu pelo fato da escavação possuir diâmetro superior ao do projeto da lona da cisterna. Essa informação deve ser reforçada nas capacitações destinadas às famílias, no intuito de aumentar os cuidados básicos de manutenção da tecnologia para garantir um 
bom funcionamento e a durabilidade da mesma, uma vez que a cisterna já se encontra em um local isolado por esses mesmos motivos.

Figura 07 - Manejo e manutenção das cisternas



Fonte: Alves, Marciely F.(2016)

Quanto ao fato do volume armazenado ser suficiente para o abastecimento em épocas de estiagem cerca de $60 \%$ dos entrevistados relatam ser suficiente e $40 \%$ relataram ser insuficiente (Figura 8).

Em campo pode se perceber que as famílias que relataram ser insuficiente são de casas que possuem somente um lado de captação, ou seja, não possuem captação para todo o telhado da casa.

Na Figura 9 está apresentado o destino dado à água da cisterna. Aproximadamente $22 \%$ fornece aos animais, 6\% utilizaram para cozinhar, $22 \%$ outros fins, e apenas $6 \%$ utilizam para beber, contrariando as recomendações deuso, ao preconizar, que a água da cisterna deve ser usada de forma consciente e gerida, por conta da quantidade de água armazenada.

Figura 08 - Percentual de famílias cuja água foi suficiente para produzir durante a estiagem.

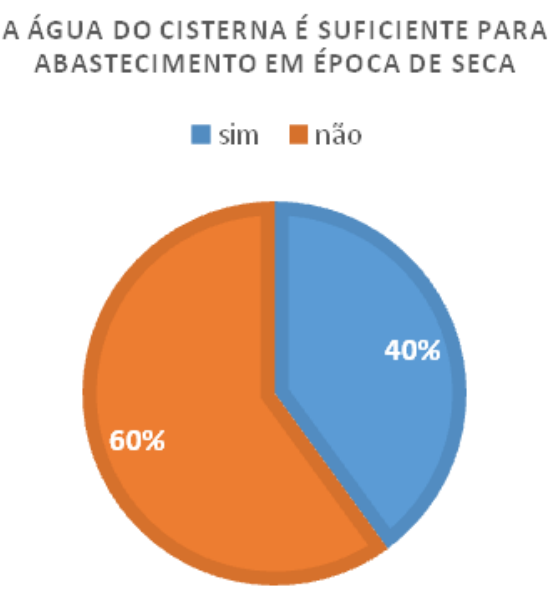

Fonte: Alves, Marciely F.(2016)

Pode se somar ao baixo índice registrado para água de consumo, (para os fins mais nobres como beber), o fato desta população residir relativamente próximo a cidade, e ter acesso a aquisição de água mineral.

Quanto sua qualidade para consumo e preparação de alimentos, os relatos das famílias foram que, nas comunidades rurais existe a presença de roedores que andam pelos telhados de captação, frente a isso as famílias preferem utilizar para outros fins.

Verifica-se com esse depoimento que ainda precisa ser trabalhada a questão de saneamento, roedores estão presentes onde há fartura de alimentos. Deve-se trabalhar com essas comunidades a questão relacionada a manutenção da limpeza ao redor das residências, a fim de evitar a proliferação desses inconvenientes seres.

Pimentel G. (2013) acompanhou as famílias na implantação das cisternas e realizou análises em laboratório, demonstrando que a água precisava ser clorada antes de ser consumida para consumo humano. 
Figura 09 - Percentual da finalidade destinada à água captada.

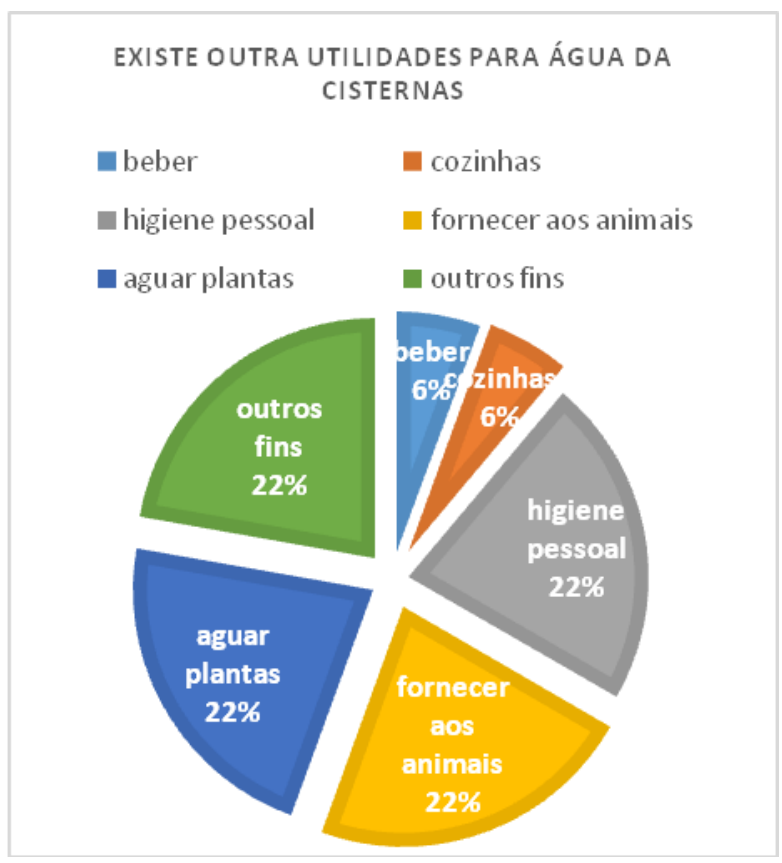

Fonte: Alves, Marciely F.

\section{Eixo segurança alimentar}

Aproximadamente $\quad 60 \%$ dos entrevistados consideram que a cisterna não promove a segurança alimentar de sua família (Figura 9). A principal justificativa foi que a água da cisterna serve somente para fins em sua maioria domésticos e dessedentação de animais. Fato que não justifica, devido o pequeno volume da cisterna, desta forma não abastece todo o período de seca.

Todas as famílias entrevistadas alegam comprar de mercados a base da alimentação, devido a produção dos lotes do assentamento ser mínima e ficando para consumo próprio de cada família, sendo somente uma família revendedora de excedentes da produção.

Dessa forma ficou evidente que a formação dessas famílias no que se refere àutilização da água da cisterna, sem desconsiderar outras possibilidades de captaçãode água da chuva e aproveitamento, deve ser reforçada e potencializada para que as famílias possam gerenciar melhor essa água para ser suficiente no período de estiagem.

Outra realidade e necessidade evidente é a disponibilidade de outra tecnologia de captação com capacidade de armazenamento destinado a produção de agricultura familiar.

Visando aumentar a disponibilidade de recurso hídrico para a produção, orienta-se trabalhar a questão das barraginhas, aumentando o volume de água para fins de uso para dessedentação de animais ou rega de plantas.

Apesar da cisterna não promover segurança alimentar para a maioria das famílias, todas alegam melhoria na qualidade de vida (Figura 10).

Figura 10 - Percentual de entrevistados que consideram ou não que a água da cisterna promove segurança alimentar

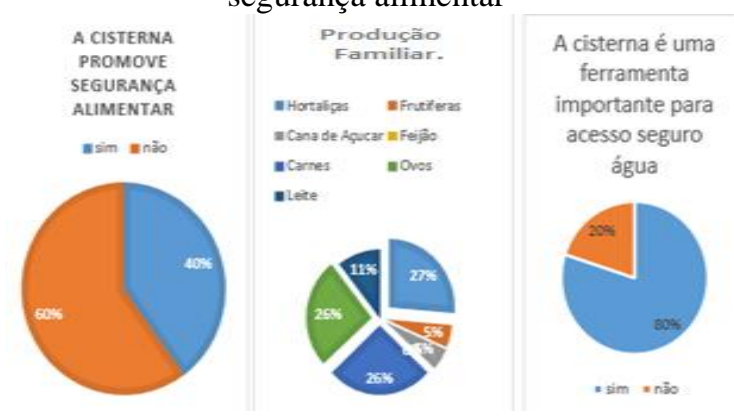

Fonte: Alves, Marciely F.

Eixo das melhorias do projeto

Quanto ao sistema de bombeamento implantado inicialmente pelo Incra $80 \%$ está ativo, sendo $20 \%$ não ativo, isso se deu devido uma família ter direcionado a bomba da cisterna para outros fins. (Figura 11)

Quanto às melhorias a serem realizadas $57 \%$ das famílias entrevistadas acreditam que poderiam ser instaladas mais cisternas, para armazenar maior volume de água em tempo de escassez, não utilizando apenas para consumo alimentar, 
mas também para outros fins voltados as atividades cotidianas da vida rural.

Figura 11 - Bombeamento e Melhorias de projeto.



Fonte: Alves, Marciely F.

\section{CONCLUSÃO}

$\begin{array}{ccc}\text { O projeto teve boa aceitação, } \\ \text { mesmo } & \text { apresentando }\end{array}$ dificuldades, como manutenção e limpeza das cisternas. É necessária a manutenção do projeto tendo em vista seus benefícios, porém, com a devida capacitação dos agricultores, bem como o acompanhamento das famílias é possível manter a qualidade da água.

A cisterna garantiu o acesso a água, proporcionando a água em períodos de estiagem, mostrando ser muito eficiente como sistema de gestão da água para famílias em zonas rurais, promovendo a sustentabilidade do homem no campo.

Estudos avançados considerando a concentração de minerais essenciais, encontrados em águas naturais, deverão ser observados em novas pesquisas.

Os autores continuam com pesquisa em cisternas implantadas na região de Nobres-MT.

\section{REFERÊNCIAS BIBLIOGRÁFICAS}

ARAÚJO, J. O. de; BRITO, L. T. de L.; CAVALCANTI, N. de B.. Água de chuva armazenada em cisterna pode incrementar qualidade nutricional da dieta das famílias. Anais... VII Congresso Brasileiro de Agroecologia, Fortaleza, Ceará, 2011.

ASSOCIAÇÃO BRASILEIRA DE NORMAS TÉCNICAS. NBR 15527: Água de chuva: aproveitamento de coberturas em áreas urbanas para fins não potáveis: requisitos. Rio de Janeiro, 2007. 8 p.

BRASIL, Ministério da Saúde MS N²914/2011, Padrões de potabilidade da água para consumo humano;

FREITAS, M. B.; FREITAS, C. M. A vigilância da qualidade da água para consumo humano Desafios e perspectivas para o Sistema Único de Saúde. Ciência \& Saúde Coletiva, Local, v.10, p.993-1004, 2005.

IBGE - Instituto Brasileiro de Geografia e Estatística. Sinopse do censo demográfico 2010. Disponível em: <http://www.censo2010.ibge.gov.br/sinopse/index. php? $\mathrm{uf}=29 \&$ dados=1> Acesso em: 14 de dezembro de 2015 .

INCRA - Instituto Nacional de Colonização e Reforma Agrária. Assentamentos em Mato Grosso em:<http://http://www.incra.gov.br/node/14454>;A cesso em: 14 de dezembro 2015.

LEWINSOHON, T. M.; PRADO, P. I. Biodiversidade Brasileira: Síntese do Estado Atual do Conhecimento. http://www.mma.gov.br/port/sbf/

chm/doc/estarte.doc; Acesso em: 13 de dezembro 2015 .

PIMENTEL GABRIEL GOMES, Análise da qualidade da água de chuva captada e tratada pelos processos de desinfecção e filtração em Assentamento localizado na área rural de Várzea Grande - MT. Trabalho de Conclusão de curso, Departamento de Engenharia Sanitária e Ambiental UFMT, 2013.

MACHADO, R. C.; MACRARI, E. L.; CRISTANTE, S. F. V.; CARARETO, C. M. A. Giardiasis and helminthiasis in children of both public and private day-care centers and junior and high schools in the city of Mirassol, São Paulo State, Brazil. Revista da Sociedade Brasileira de Medicina Tropical, v. 32, n. 1, p. 697-704, 1999.

PONTES, E. T. M.; MACHADO, T. A. Programa um milhão de cisternas rurais no nordeste brasileiro: políticas públicas, desenvolvimento sustentável e convivência com o semi-árido. In: XIX Encontro Nacional de Geografia Agrária. São Paulo, SP.Anais... São Paulo: USP, 2009.

SILVA, N. A.; e contribuintes. Impactos Socioeconômicos do Projeto de Cisternas II, em Comunidades do Município de Ibipeba, Bahia. In: Enciclopédia Biosfera - Centro Cientifico Conhecer - Goiânia, 2013. 


\section{Anexo}

\section{Formulário Aplicado}

Número total de pessoas na família:

De 02 a 03 indivíduos ( )

De 03 a 04 indivíduos ( )

De 04 a 05 indivíduos ( )

De 05 a 06 indivíduos ( )

1- Crianças:

Jovens:

Idosos:___ Adultos:

2- Quais eram as fontes de abastecimento de água para produzir antes da cisterna?

Nenhuma ( )

Poço Tubular ( )

Poço Artesiano ( )

3- Renda média da família:

Ate 1 salário mínimo ( )

De 1 a 2 salários mínimo ( )

De 2 a 3 salários mínimos ( )

De 3 a 4 salários mínimos ( )

De 5 a 6 salários mínimos ( )

4- A família recebe algum benefício social dos governos federal, estadual ou municipal?

Se sim, qual ou quais?

Sim ( ) Qual

Não ( )

5- Quais são os meios utilizados para manter a renda da casa durante todo o ano?
( ) Benefícios assistenciais
( ) Aposentadoria
( ) Assaliado particular
( ) Agricultura Familiar

6- Quais os tipos de alimentos produzidos pela família atualmente?

7- Já lavou sua cisterna alguma vez depois da construção?
( ) $\mathrm{Sim}$
( ) Não

8- Possui bombeamento?
( ) $\mathrm{Sim}$
( ) Não

9- A água da cisterna é suficiente para CONSUMO DA FAMILIA durante os períodos de estiagem?

( ) $\mathrm{Sim}$

( ) Não

10-Existem outras utilidades para água armazenada nas cisternas de produção?
a) beber
b) cozinhar
c) higiene pessoal
d) fornecer aos animais
e) aguar plantas
f) outros fins

11- A cisterna é uma ferramenta importante para promover o segurança alimentar?
( ) $\mathrm{Sim}$
( ) Não

12- O que poderia ser melhorado no projeto?

13- A cisterna é uma ferramenta importante para promover o acesso seguro a água?

( ) $\mathrm{Sim}$

( ) Não 